\title{
Left ventricular function in diabetes mellitus II: Relation between clinical features and left ventricular function
}

\author{
L M SHAPIRO*, B A LEATHERDALE, J MACKINNON, R F FLETCHER \\ From the Department of Cardiology, Dudley Road Hospital, Birmingham, and the Department of \\ Diabetes and Endocrinology, Dudley Road Hospital, Birmingham
}

SUMMARY We have shown a close relation between clinical microvascular complications and abnormalities of left ventricular function in 185 established diabetics without clinical heart disease.

In 50 insulin-dependent diabetics who presented at under 20 years of age there was a correlation between the duration of diabetes and the isovolumic relaxation time, minimal dimension to mitral valve opening, and ratio of pre-ejection period to left ventricular ejection time.

Diabetics with mild microvascular complications were similar to diabetics with no complications except for minor prolongation of the diastolic time intervals. Those with severe complications were significantly different from diabetics with milder complications and normal controls in all variables of left ventricular function.

A close relation between left ventricular function and the microvascular complications index (code 0 when no complications to code 7 when all present and severe) was found for the following variables: isovolumic relaxation time, the interval from minimal dimension to mitral valve opening, ratio of preejection period to left ventricular ejection time, and pre-ejection period index.

It is concluded that in diabetes abnormalities of left ventricular function are related to duration of disease and complications; and that a diabetic specific heart muscle disorder occurs frequently in patients with severe microvascular complications.

Necropsy studies have suggested the existence of a specific diabetic cardiomyopathy ${ }^{12}$ or cardiopathy ${ }^{3}$ caused by myocardial involvement by diabetic microvascular disease. Frequent abnormalities of left ventricular function attributed to a "preclinical cardiomyopathy" have been detected by haemodynaemic $^{4} 5$ and non-invasive methods ${ }^{6-8}$ in diabetics without clinical heart disease. Histological and necropsy reports are, however, conflicting on the presence, extent, and significance of atherosclerosis and diabetic microvascular involvement of the coronary circulation..$^{34-12}$ If there is a specific diabetic disorder of the myocardium there should be a strong relation between the degree of clinical microvascular disease and left ventricular function, and the frequency and severity of abnormalities should increase with the duration of diabetes, as

\footnotetext{
* Present address: Department of Clinical Cardiology, Hammersmith Hospital, Du Cane Road, London W12 OH5

Received for publication 21 July 1980
}

shown with retinopathy and proteinuria. ${ }^{13}$

The purpose of this study was to determine the relation of left ventricular function to the clinical features of diabetes in a large sample of diabetic patients.

\section{Patients and methods}

The patients, normal controls, and methods of measuring left ventricular function have been described in the first part of this report. ${ }^{14}$ From the original sample of 212 diabetics, 185 patients with no clinical evidence of heart disease (angina or heart failure) were subdivided into the following groups.

(a) Insulin-dependent patients who presented at under 20 years of age were used to determine relations to the duration of diabetes $(n=50$, mean duration $10 \pm 9$ years, range 0 to 39 years).

(b) (i) Diabetics with no microvascular complications $(n=54)$. 
(ii) Diabetics with mild microvascular complications $(n=75)$, mild background retinopathy, and/or mild proteinuria.

(iii) Diabetics with severe microvascular complications $(n=44)$, heavy proteinuria, and/or proliferative retinopathy.

(iv) Recently diagnosed (within 3 years) insulin-dependent diabetics $(n=12)$.

The diabetic patients were graded according to the presence and extent of diabetic complications (Table 1), and an index of microvascular complications was constructed. This allowed for a scale from zero (with no complications) to seven (when all were present and severe) (Fig.).

Student's $t$ tests were used to compare mean differences between normal and diabetic subgroups. The degree of relation between left ventricular function and the microvascular complications index and duration of diabetes was estimated with Kendall's rank ord $\approx$ r correlation coefficient $(\tau)$ and Pearson's correlation coefficient ( $r$ ), respectively.

\section{Results}

There was a significant correlation between the duration of diabetes and the isovolumic relaxation time $(r=0.58, p<0.001)$, minimal dimension to mitral valve opening $(r=0.71, p<0.001)$, and loss of beat-to-beat variation $(r=0.79, p<0.001)$ in the young insulin-dependent diabetics. Systolic time intervals, ratio of pre-ejection period (PEP) to left ventricular ejection time (LVET) $(r=0.38, p<0.01)$, and PEP index ( $r=0.34$, not significant) were less strongly correlated. The microvascular complications index was significantly correlated with duration of diabetes $(\tau=0.56, p<0.001)$.

The recently diagnosed insulin-dependent diabetics $(n=12)$ were normal in all variables. In comparison, diabetics with no complications had minor prolongation of both diastolic time intervals $(p<0.05)$. Diabetics with mild complications

Table 1 Scheme for grading microvascular complications

\begin{tabular}{ll}
\hline Code & Retinopathy \\
0 & None \\
1 & Mild background: less than 10 red dots per eye \\
2 & Severe background: greater than 10 red dots per eye \\
3 & Proliferative \\
& Proteinuria \\
0 & None \\
1 & Mild: one or two plus proteinuria \\
2 & Severe: heavy proteinuria \\
& Neuropathy \\
0 & None \\
1 & Mild: absent ankle jerks and vibration sense in feet \\
2 & Severe: further evidence of neuropathy including auto- \\
& nomic neuropathy \\
\hline
\end{tabular}

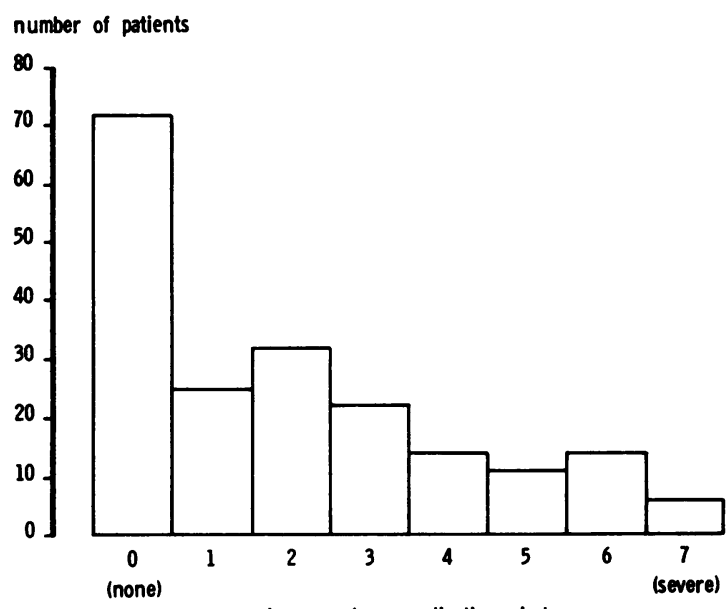

Fig. The distribution of the microvascular complications index $(n=185)$.

$(\mathrm{n}=75)$ had reduced beat-to-beat variation $(\mathrm{p}<0.001)$, prolonged isovolumic relaxation time $(\mathrm{p}<0.001)$, and interval from minimal dimension to mitral valve opening $(p<0.001)$ compared with recently diagnosed diabetics and normal. Those with severe microvascular complications differed significantly $(p<0.001)$ from all other subgroups in all variables except in the interval from minimal dimension to mitral valve opening with diabetics with mild complications (Table 2).

There was a correlation between the microvascular complications index and variables of impaired left ventricular function in the 185 diabetic patients without clinical heart disease: isovolumic relaxation time $(\tau=0.25, p<0.001)$, minimal dimension to mitral valve opening $(\tau=0.17$, $\mathrm{p}<0.001)$, PEP/LVET ratio $(\tau=0.22, \mathrm{p}<0.001)$, PEP index $(\tau=0.2, \mathrm{p}<0.001)$, and loss of beat-tobeat variation $(\tau=0.48, p<0.001)$. There was no relation with dimension change during isovolumic relaxation.

\section{Discussion}

To study the evolution of a disorder and its prognosis, serial measurements in a longitudinal study are the ideal; the long time course of diabetic heart disease makes this difficult. A somewhat less satisfactory alternative is a cross-sectional study involving a large number of subjects with various durations and types of diabetes. The study reported is of the latter type.

In insulin-dependent diabetics under the age of 
20 years, clinical presentation was assumed to represent onset. This may not be correct but it is unlikely to introduce a substantial error. In fact diabetics within a few years of presentation were free from complications and all had normal left ventricular function. There was a gradual increase in abnormalities of left ventricular function as the frequency of microvascular complications and duration of diabetes increased, and after 20 years diastolic abnormalities were common. A similar relation exists between the presence of retinopathy and proteinuria and the duration in insulindependent diabetics. ${ }^{13}$

Established diabetics with no complications had significantly prolonged isovolumic relaxation time and interval from minimal dimension to mitral valve opening. Diabetics with mild proteinuria or background retinopathy tended to have abnormalities of left ventricular function intermediate between those of patients with no and those with severe microvascular disease. The latter had raised PEP/LVET and prolonged PEP index ${ }^{7}$ and isovolumic relaxation time. The interval from minimal dimension to mitral valve opening was also prolonged and there was no dimension change during the isovolumic phase. ${ }^{8}$ No patient with severe microvascular disease had normal diastolic function and most had abnormal systolic time intervals.

As expected, loss of beat-to-beat variation was significantly correlated both with the index of microvascular complications and duration of diabetes in insulin-dependent diabetics. The isovolumic relaxation time and interval from minimal dimension to mitral valve opening were significantly correlated with the index, but the ratio of PEP/LVET and PEP index were less strongly related. This emphasises the continuous relation between the severity of microvascular complications and impairment of left ventricular function. As the duration of diabetes, complications, and metabolic abnormalities are closely associated, it does not necessarily imply a causal relation but there seems good evidence for a similar aetiological basis.
The cause of impaired left ventricular function could be the result of microvascular disease, metabolic abnormalities, and/or coronary artery disease. Analysis of the isovolumic period and the associated wall motion shows the incoordinate ${ }^{15} 16$ nature of the dyskinetic ventricle in coronary artery disease. In the first part of this report we found this in patients with angina both with and without diabetes and this confirmed an earlier impression ${ }^{17}$ that there was also a high incidence of incoordination in diabetics without chest pain, who are presumed to have asymptomatic but significant coronary artery disease.

Necropsy ${ }^{1-3}$ and biopsy ${ }^{42}$ studies indicate that diabetics frequently have abnormalities of coronary microcirculation and myocardium: endothelial proliferation, perivascular fibrosis, glycoprotein deposition, and interstitial myocardial fibrosis (the most frequent) can be extensive and are independent of coronary atherosclerosis. The recent demonstration of capillary microaneurysms in silicone rubber injected preparations of diabetic myocardium $^{18}$ suggests that the vascular abnormalities are similar to those in the retina. The myocardium responds to injury by fibrosis as in myocardial infarction and chronic ischaemia; the interstitial fibrosis frequently shown in diabetics may be the myocardial response to small vessel involvement and the resultant diffuse ischaemia. The vascular abnormalities would eventually reduce coronary perfusion and the infiltration change left ventricular properties.

We propose that myocardial involvement in diabetes is functionally important and may occur relatively early in the course of the disease, initially impairing early diastolic relaxation, and, when more extensive, probably in combination with reduced myocardial perfusion, further impairing relaxation and then contraction. Such abnormalities have been called a diabetic cardiomyopathy, ${ }^{3-5} 89$ but as they are secondary to a systemic disorder, the term "diabetic specific heart muscle disorder" should be used. ${ }^{19}$

Table 2 Measurements of left ventricular function in diabetics without clinical heart disease

\begin{tabular}{|c|c|c|c|c|c|c|}
\hline & No. & $\begin{array}{l}\text { Beat-to-beat } \\
\text { variation }\end{array}$ & $\begin{array}{l}P E P / L V E T \\
(\%)\end{array}$ & $\begin{array}{l}P E P \text { index } \\
(m s)\end{array}$ & $\begin{array}{l}\text { Isovolumic } \\
\text { relaxation } \\
\text { time } \\
\text { (ms) }\end{array}$ & $\begin{array}{l}\text { Minimal dimension } \\
\text { to mitral valve } \\
\text { opening } \\
(\mathrm{ms})\end{array}$ \\
\hline $\begin{array}{l}\text { Normal } \\
\text { Diabetics }\end{array}$ & 50 & $27 \pm 14$ & $31 \pm 4$ & $123 \pm 4$ & $58 \pm 9$ & $12 \pm 13$ \\
\hline $\begin{array}{l}\text { Recently diagnosed insulin-dependent diabetics } \\
\text { No complications } \\
\text { Background retinopathy or mild proteinuria } \\
\text { Proliferative retinopathy or heavy proteinuria }\end{array}$ & $\begin{array}{l}12 \\
54 \\
75 \\
44\end{array}$ & $\begin{array}{r}24 \pm 12 \\
18 \pm 10 \\
10 \pm 8 \\
4 \pm 3\end{array}$ & $\begin{array}{l}31 \pm 1 \\
33 \pm 6 \\
34 \pm 7 \\
39 \pm 8\end{array}$ & $\begin{array}{l}122 \pm 5 \\
125 \pm 13 \\
126 \pm 14 \\
136 \pm 14\end{array}$ & $\begin{array}{l}56 \pm 11 \\
68 \pm 21 \\
70 \pm 19 \\
87 \pm 21\end{array}$ & $\begin{array}{l}10 \pm 12 \\
21 \pm 28 \\
32 \pm 31 \\
39 \pm 24\end{array}$ \\
\hline
\end{tabular}




\section{References}

1 Rubler S, Dlugash J, Yuceoglu YZ, Kumral T, Branwood AW, Grishman A. New type of cardiomyopathy associated with diabetic glomerulosclerosis. Am f Cardiol 1972; 30: 595-602.

2 Hamby RI, Zoneraich S, Sherman L. Diabetic cardiomyopathy. $\mathcal{F} A M A$ 1974; 229: 1749-54.

3 Ledet T. Diabetic cardiopathy. Quantitative histological studies of the heart from young juvenile diabetics. Acta Pathol Microbiol Scand [A] 1976; 84: 421-8.

4 Regan TJ, Lyons MM, Ahmed SS, et al. Evidence for cardiomyopathy in familial diabetes mellitus. f Clin Invest 1977; 60: 885-99.

5 D'Elia JA, Weinrauch LA, Healy RW, Libertino JA, Bradley RF, Leland OS Jr. Myocardial dysfunction without coronary artery disease in diabetic renal failure. Am f Cardiol 1979; 43: 193-9.

6 Ahmed SS, Jaferi GA, Narang RM, Regan TJ. Preclinical abnormality of left ventricular function in diabetes mellitus. Am Heart $\mathcal{F}$ 1975; 89: 153-8.

7 Seneviratne BIB. Diabetic cardiomyopathy: the preclinical phase. $\mathrm{Br}$ Med f 1977; i: 1444-6.

8 Sanderson JE, Brown DJ, Rivellese A, Kohner E. Diabetic cardiomyopathy? An echocardiographic study of young diabetics. $\mathrm{Br}$ Med f 1978; i: 404-7.

9 Dash H, Johnson RA, Dinsmore RE, Francis CK, Harthorne JW. Cardiomyopathic syndrome due to coronary artery disease. II: Increased prevalence in patients with diabetes mellitus: a matched pair analysis. $B r$ Heart $\mathcal{F}$ 1977; 39: 740-7.

10 Boucher CA, Fallon JT, Johnson RA, Yurchak PM. Cardiomyopathic syndrome caused by coronary artery disease. III: Prospective clinicopathological study of its prevalence among patients with clinically unexplained chronic heart failure. $B r$ Heart $\mathcal{F}$ 1979; 41: 613-20.
11 Crall FV Jr, Roberts WC. The extramural and intramural coronary arteries in juvenile diabetes mellitus. Am ₹ Med 1978; 64: 221-30.

12 Pearce MB, Bulloch RT, Kizziar JC. Myocardial small vessel disease in patients with diabetes mellitus (abstract). Circulation 1973; 48: suppl 4: 6.

13 Knowles HC Jr, Guest GM, Lampe J, Kessler M, Skillman TG. The course of juvenile diabetes treated with unmeasured diet. Diabetes 1965; 14: 239-73.

14 Shapiro LM, Howat AP, Calter MM. Left ventricular function in diabetes mellitus. I: Methodology, and prevalence, and spectrum of abnormalities. $\mathrm{Br}$ Heart $\mathcal{F} 1981$; 45: 122-8.

15 Chen W, Gibson D. Relation of isovolumic relaxation to left ventricular wall movement in man. Br Heart $\mathcal{F}$ 1979; 42: 51-6.

16 Gibson DG, Doran JH, Traill TA, Brown DJ. Regional abnormalities of left ventricular wall movement during isovolumic relaxation in patients with ischaemic heart disease. Eur $\mathcal{F}$ Cardiol 1978; 7, suppl: 251-64.

17 Shapiro LM, Leatherdale BA, Coyne ME, Fletcher RF, Mackinnon J. Prospective study of heart disease in untreated maturity onset diabetics. Br Heart $\mathcal{F}$ $1980 ; 44$ : 342-8.

18 Factor SM, Okun EM, Minase T. Capillary microaneurysms in the human diabetic heart. $N$ Engl $f$ Med 1980: 302: 384-8.

19 Goodwin JF, Oakley CM. The cardiomyopathies. Br Heart $\mathcal{F} 1972 ; 34: 545-52$.

Requests for reprints to Dr L M Shapiro, Department of Clinical Cardiology, Hammersmith Hospital, Du Cane Road, London W12 0H5. 